\title{
Association of genetic polymorphisms on methotrexate toxicity in patients with rheumatoid arthritis
} María José Zarzuelo Romero ${ }^{1}$, María del Mar Maldonado Montoro², Cristina Pérez Ramírez ${ }^{3}$,
Noelia Márquez Pete ${ }^{4}$, Almudena Sánchez Martín ${ }^{4}$, Fernando Martínez Martínez
Miguel Ángel Calleja Hernández ${ }^{3}$, María Carmen Ramírez Tortosa ${ }^{5}$, Alberto Jiménez Morales ${ }^{4}$

\author{
'Department of Pharmacy and Pharmaceutical Technology, Social and Legal \\ Assistance Pharmacy Section, Faculty of Pharmacy, University of Granada, Granada, \\ Spain \\ ${ }^{2}$ Clinical Analysis Service, Hospital Campus de la Salud, Granada, Spain \\ ${ }^{3}$ Pharmacy Service, Pharmacogenetics Unit, University Hospital Virgen Macarena, \\ Sevilla, Spain \\ ${ }^{4}$ Pharmacy Service, Pharmacogenetics Unit, University Hospital Virgen de las Nieves, \\ UGC Provincial de Farmacia de Granada, Granada, Spain \\ ${ }^{5}$ Department of Biochemistry, Faculty of Pharmacy, University of Granada, Granada, \\ Spain
}

Submitted: 16 April 2020

Accepted: 19 June 2020

Arch Med Sci

DOI: https://doi.org/10.5114/aoms.2020.97360

Copyright (c) 2020 Termedia \& Banach

\begin{abstract}
Introduction: Methotrexate (MTX) is the treatment of choice for patients with rheumatoid arthritis (RA). However, it has been found to produce toxicity in some patients. Different polymorphisms can play a part in inter-individual differences in toxicity. Our aim is therefore to determine the influence of gene polymorphisms in the MTX metabolic pathway, such as MTHFR (rs1801133 and rs1801131), MTHFD1 (rs2236225), MTR (rs1805087), and ABCC2 (rs4148396), on toxicity in MTX treatment among Caucasian patients diagnosed with RA.

Material and methods: Real-time polymnerase chain reaction (PCR) analysis with TaqMan probes was performed on these polymorphisms in 200 patients in a retrospective study.

Results: Patients with TT genotype and C allele for MTHFR rs1801133 gene polymorphism presented a higher risk of anaemia $(p=0.0304 ; \mathrm{OR}=3.70$; $95 \% \mathrm{Cl}: 1.10-12.34)$ and dizziness $(p=0.0438$; OR $=8.15 ; 95 \% \mathrm{Cl}: 1.61-$ $148.68)$. Patients with MTHFR rs $1801131-C$ allele or CC genotype presented a higher risk of mucositis ( $p=0.0188$; OR $=3.02 ; 95 \% \mathrm{Cl}: 1.22-7.91)$, acneiform rash $(p=0.0322 ; \mathrm{OR}=5.74 ; 95 \% \mathrm{Cl}: 1.34-39.21)$, and alopecia $(p=0.0072 ; \mathrm{OR}=5.11 ; 95 \% \mathrm{Cl}: 1.37-17.70)$. Patients with MTR rs $1805087-$ CC genotype presented a higher risk of anosmia $(p=0.0038$; OR $=98.00$; $95 \% \mathrm{Cl}: 3.16$-infinite); patients with the TT genotype or T allele for MTHFD 1 rs2236225 presented a higher risk of liver failure $(p=0.00229 ; \mathrm{OR}=2.34$; $95 \% \mathrm{Cl}: 1.14-4.96)$ and alopecia $(p=0.0248 ; \mathrm{OR}=3.83 ; 95 \% \mathrm{Cl}: 1.10-13.30)$, and patients with the TT genotype for ABCC2 rs4148396 polymorphism ( $p=$ $0.0466 ; \mathrm{OR}=2.67 ; 95 \% \mathrm{Cl}: 0.98-6.94)$ presented a higher risk of headaches. Conclusions: Pharmacogenomic analysis of these polymorphisms may facilitate decision-making in relation to MTX treatment toxicity among RA patients.
\end{abstract}

Key words: rheumatoid arthritis, methotrexate, toxicity, polymorphisms.

\section{Corresponding author:}

Cristina Pérez Ramírez PhD

University Hospital Virgen

Macarena

Pharmacy Service

Dr. Fedriani 3

41009 Sevilla, Spain

Phone: +34955008000

E-mail:

cperezramirez87@gmail.com 
María José Zarzuelo Romero, María del Mar Maldonado Montoro, Cristina Pérez Ramírez, Noelia Márquez Pete, Almudena Sánchez Martín, Fernando Martínez Martínez, Miguel Ángel Calleja Hernández, María Carmen Ramírez Tortosa, Alberto Jiménez Morales

\section{Introduction}

Rheumatoid arthritis (RA) is a chronic inflammatory autoimmune disease characterised by inflammation of the synovial membrane in joints, causing joint destruction and consequently pain and functional disability, diminishing quality of life among patients [1-5]. RA affects approximately $0.5 \%$ of the adult population globally $[6,7]$. The disease is predominantly treated using disease-modifying anti-rheumatic drugs (DMARDS) and nonsteroidal anti-inflammatory drugs (NSAIDs) $[8,9]$. These drugs act by reducing inflammation and delaying bone erosion, and, therefore, they slow down the progression of the disease [10]. Methotrexate (MTX) is the first-line treatment for this disease both as monotherapy and as an adjuvant to biological therapies, due to its high efficacy and rapid action [11, 12]. However, there is considerable interindividual variability in MTX toxicity [13]. Previous studies have found that one-third of patients on MTX treatment do not reach the therapeutic goal due to lack of response to the drug, development of toxicity or loss of efficacy over time [14-17]. Among the most frequent adverse effects are gastrointestinal disorders, liver toxicity, skin reactions, and bone marrow disorders $[18,19]$. The factors responsible for this variable toxicity in MTX treatment are not yet fully understood, but recently the genetic polymorphisms linked to the MTX metabolic pathway have become the targets of study for understanding MTX toxicity [20-24].

MTX is a folic acid analogue with anti-inflammatory and anti-proliferative properties [25, 26]. It acts by inhibiting various enzymes in the synthesis pathway of folate, methionine, adenosine, and nucleotides [25], significant among which is methylenetetrahydrofolate reductase (MTHFR). The protein encoded by this gene catalyses the conversion of 5,10-methylenetetrahydrofolate to 5-methyltetrahydrofolate, a co-substrate for homocysteine remethylation to methionine [27]. Two polymorphisms in this enzyme play a part in metabolising MTX. SNP (Single Nucleotide Polymorphism) MTHFR 677C> T (rs1801133) leads to the substitution of alanine for valine at position 233 (Ala233Val) of the protein, reducing the activity of the enzyme. Previous studies have found a link between TT+CT genotypes and MTX liver toxicity, due to increased serum levels of liver enzymes and homocysteine $[28,29]$. Another of the polymorphisms studied is MTHFR 1298A>C (rs1801131), which leads to the substitution of glutamine for alanine at codon 429 (Glu429Ala). The G allele has previously been linked to increased risk of adverse effects such as neurotoxicity and liver toxicity [30, 31]. The methylenetetrahydrofolate dehydrogenase 1 (MTHFD1) encodes a protein that possesses three distinct enzymatic activities: 5,10-methylenetetrahydrofolate dehydrogenase, 5,10-methenyltetrahydrofolate cyclohydrolase, and 10-formyltetrahydrofolate synthetase. Each of these activities catalyses one of three sequential reactions in the interconversion of 1-carbon derivatives of tetrahydrofolate, which are substrates for methionine, thymidylate, and de novo purine syntheses. The polymorphism 1958G >A (rs2236225) leads to the substitution of arginine for glycine at gene position 653 (Arg$653 \mathrm{Gln})$, reducing the enzymatic activity of the complex [32]. Another enzyme found on the folic acid metabolic pathway is 5-methyltetrahydrofolate-homocysteine methyltransferase (MTR), also known as cobalamin-dependent methionine synthase, which catalyses the final step in methionine biosynthesis [28]. An SNP in MTR gene (2756A>G rs1805087) has been found to reduce enzyme activity $[33,34]$.

MTX is transported across the cell membrane by a series of transporter proteins, significant amongst which are ABCB1 (P-glycoprotein) and multidrug resistance-associated protein 2 (ABCC2). The membrane-associated proteins encoded by these genes are members of the superfamily of ATP-binding cassette $(A B C)$ transporters. $A B C$ proteins transport various molecules across extra- and intra-cellular membranes [35]. The $A B C B 13435 C>T$ (rs1045642) gene polymorphism has been found to affect response to the drug; specifically, genotype CC could play a part in reducing response to therapy [36]. Similarly, the CT genotype has been linked to increased risk of gastrointestinal toxicity in 336 RA patients of Indian origin [37]. Another of the polymorphisms involved is (rs4148396) in the $A B C C 2$ gene, a transporter protein involved in eliminating metabolites and located on the surface of hepatocytes, the intestine, and the proximal tubules [38]. In a study on 309 Caucasian RA patients on MTX treatment, the CC genotype was found to be associated with increased risk of alopecia [39]. Finally, an SNP in TLR4 (Toll-4 receptor) (896A>G; rs4986790) gene, which codified a protein member of the Toll-like receptor (TLR) family and plays a fundamental role in pathogen recognition and activation of innate immunity, has been linked to the development of mucositis in patients being treated with folic acid and MTX [40].

This was the conceptual framework for our study evaluating the influence of polymorphisms in the genes along the MTX metabolic pathway, including MTHFR 677C $>$ T (rs1801133), 1298A $>C$ (rs1801131), MTHFD1 1958G>A (rs2236225), MTR 2756A $>\mathrm{G}$ (rs1805087), ABCB1 3435C $>\mathrm{T}$ (rs1045642), ABCC2 C>T (rs4148396), and TLR4 896A>G ( $\mathrm{ss} 4986790)$, on specific types of toxicity of MTX treatment that have not been previously described among Caucasian RA patients. 


\section{Material and methods}

\section{Study design}

An observational, retrospective cohort study conducted in the Virgen de las Nieves University Hospital in Granada (HUVN) with the approval of the reference Ethics Committee in compliance with the Helsinki Declaration. Informed consent was obtained from all patients prior to their inclusion in the study, and their data were treated confidentially.

\section{Target population}

The study recruited 200 Caucasian patients, aged over 18 years, and diagnosed with RA as per American College of Rheumatology (ACR) criteria, who were on, or had been on, MTX treatment for at least 1 month. The initial dose was $15 \mathrm{mg} /$ week orally, with escalation from $5 \mathrm{mg} / \mathrm{month}$ to $25-$ $30 \mathrm{mg} /$ week or to the maximum tolerable dose. In the case of an insufficient response it was changed to subcutaneous administration [41, 42].

\section{Study location and timeframe}

Patients diagnosed with RA and on MTX treatment between February 1990 and June 2018, in HUVN Rheumatology and Pharmacy Departments.

\section{Sociodemographic and clinical variables}

The data collected were: sex, age when diagnosed with RA, duration of MTX treatment, smoking status, baseline rheumatoid factor (RF) value, baseline DAS28 [43] value, and adverse reactions relating to blood disorders (anaemia, neutropaenia, macrocytosis, and thrombocytopaenia), smelling (anosmia), digestive system (diarrhoea, nausea and vomiting, mucositis), liver failure, nervous system (dizziness and headaches), psychiatric disorders (anxiety), reproductive system (metrorrhagia), respiratory disorders (pulmonary fibrosis), and skin and subcutaneous tissue disorders (alopecia and acneiform rash).

EULAR response was according to the guidelines given by the European League Against Rheumatism, and was classified as satisfactory (presenting DAS28 3.2 and DAS28 improvement $>1.2$ ) or unsatisfactory (presenting DAS28 $\geq 3.2$ and DAS28 improvement $\geq 1.2$ ).

Remission and low disease activity were considered when patients achieved DAS2 $8<2.4$ and DAS28 $<3.6$, respectively.

\section{Genetic variables}

\section{DNA isolation}

Saliva samples were collected in $50 \mathrm{ml} \mathrm{BD}$ Fal$\mathrm{con}^{\mathrm{TM}}$ conical tubes (BD, Plymouth, UK). DNA isola- tion was performed using the QIAamp DNA Mini Kit (QiagenGmBH, Hilden, Germany) according to the manufacturer's instructions for DNA purification from blood or saliva and stored at $-40^{\circ} \mathrm{C}$.

\section{Detection of genetic polymorphisms}

The genetic polymorphisms identified as being involved in MTX toxicity $-A B C B 13435 C>T$ (rs1045642), $A B C C 2 C>T(r s 4148396), M T H F R 677 C>T(r s 1801133)$, MTHFR 1298A $>C \quad(\mathrm{rs} 1801131), \quad M T R \quad 2756 \mathrm{~A}>\mathrm{G}$ (rs1805087), MTHFD1 1958G>A (rs2236225) and TLR4 896A>G (rs4986790) - were analysed using real-time PCR with $\operatorname{TaqMan}^{\circledast}$ probes. The assay ID used for gen $A B C B 1$ (rs1045642) is C_7586657_20, for $A B C C 2$ (rs4148396) is C_11305432_10, for MTHFR (rs1801133) is C_1202883_20, for MTHFR (rs1801131) is C_850486_20, for MTR (rs1805087) is C_12005959_10, for MTHFD1 (rs2236225) is C_1376137_10, and for TLR4 (rs4986790) is C_11722238_20.

\section{Toxicity variables}

Toxicity was evaluated using version 4.0 of Common Terminology Criteria for Adverse Events (CTCAE). According to the severity of the adverse reaction, it was graded $0-2$ and $3-4$. This study considered adverse events of grade 3-4, dichotomised into the presence or absence of type of adverse reaction.

\section{Statistical analysis}

Quantitative data were expressed as mean ( \pm standard deviation) for normal-distribution variables or medians and percentiles (25 and 75) for non-normal-distribution variables.

Bivariate analysis was used to evaluate the link between toxicity and polymorphisms using Fisher's exact test and odds ratio (OR) with the appropriate $95 \%$ confidence interval $(\mathrm{Cl})$.

Differences in distribution of genotypes for toxicity were analysed using $3 \times 2$ tables for each genotype. Values of $p<0.05$ were considered statistically significant. Strength of association between RA patients and genotypes was estimated using relative risk (RR) with $95 \% \mathrm{Cl}$.

Descriptive analysis was performed using $R$ 3.0.1 [44].

The Hardy-Weinberg equilibrium and pairwise haplotype frequencies were estimated using the free, open-source whole genome association analysis toolset PLINK [45].

\section{Results}

\section{Patient characteristics}

The baseline characteristics of the 200 RA patients are shown in Table I. Median age was 
María José Zarzuelo Romero, María del Mar Maldonado Montoro, Cristina Pérez Ramírez, Noelia Márquez Pete, Almudena Sánchez Martín, Fernando Martínez Martínez, Miguel Ángel Calleja Hernández, María Carmen Ramírez Tortosa, Alberto Jiménez Morales

Table I. Clinical-pathological characteristics of the 200 RA patients treated with methotrexate

\begin{tabular}{|c|c|c|c|c|c|}
\hline Parameter & $N$ & $\%$ & Parameter & $N$ & $\%$ \\
\hline \multicolumn{3}{|l|}{ Gender: } & \multicolumn{3}{|l|}{ Nausea and vomiting: } \\
\hline Female & 161 & 80.5 & Yes & 46 & 23.0 \\
\hline Male & 39 & 19.5 & No & 154 & 77.0 \\
\hline Age at AR diagnosis [years]: & $45(35-53)$ & & \multicolumn{3}{|l|}{ Mucositis: } \\
\hline$\leq 45$ & 102 & 51.0 & Yes & 22 & 11.0 \\
\hline$>45$ & 98 & 49.0 & No & 178 & 89.0 \\
\hline \multirow{2}{*}{$\begin{array}{l}\text { Duration of methotrexate } \\
\text { treatment [months]: }\end{array}$} & \multirow{2}{*}{\multicolumn{2}{|c|}{$46(17-88)$}} & \multirow{2}{*}{\multicolumn{3}{|c|}{$\begin{array}{l}\text { Hepatobiliary disorders: } \\
\text { Liver failure: }\end{array}$}} \\
\hline & & & & & \\
\hline$\leq 46$ & 102 & 51.0 & Yes & 90 & 46.4 \\
\hline$>46$ & 98 & 49.0 & No & 104 & 53.6 \\
\hline \multicolumn{3}{|l|}{ Smoking status: } & \multirow{2}{*}{\multicolumn{3}{|c|}{$\begin{array}{l}\text { Nervous system disorders: } \\
\text { Dizziness: }\end{array}$}} \\
\hline Current-smokers & 45 & 22.5 & & & \\
\hline Former-smokers & 12 & 6.0 & Yes & 18 & 9.0 \\
\hline Non-smokers & 143 & 71.5 & No & 182 & 91.0 \\
\hline \multicolumn{3}{|l|}{ Baseline FR status: } & \multicolumn{3}{|l|}{ Headache: } \\
\hline Negative & 63 & 31.7 & Yes & 20 & 10 \\
\hline Positive & 136 & 68.3 & No & 180 & 90 \\
\hline \multicolumn{3}{|l|}{ Baseline DAS28 status } & \multirow{2}{*}{\multicolumn{3}{|c|}{$\begin{array}{l}\text { Psychiatric disorders: } \\
\text { Anxiety: }\end{array}$}} \\
\hline$\leq 5.42$ & 98 & 49.3 & & & \\
\hline$>5.42$ & 101 & 50.7 & Yes & 1 & 0.5 \\
\hline \multicolumn{3}{|l|}{ Blood system disorders: } & No & 199 & 99.5 \\
\hline \multicolumn{3}{|l|}{ Anaemia: } & \multirow{3}{*}{\multicolumn{3}{|c|}{$\begin{array}{l}\text { Reproductive system and } \\
\text { breast disorders: } \\
\text { Metrorrhagia }\end{array}$}} \\
\hline Yes & 12 & 6.0 & & & \\
\hline No & 188 & 94.0 & & & \\
\hline \multicolumn{3}{|l|}{ Neutropaenia: } & Yes & 3 & 1.5 \\
\hline Yes & 15 & 7.5 & No & 197 & 98.5 \\
\hline No & 185 & 92.5 & \multirow{3}{*}{\multicolumn{3}{|c|}{$\begin{array}{l}\text { Respiratory, thoracic and } \\
\text { mediastinal disorders: } \\
\text { Pulmonary fibrosis }\end{array}$}} \\
\hline \multicolumn{3}{|l|}{ Macrocytosis: } & & & \\
\hline Yes & 5 & 2.5 & & & \\
\hline No & 195 & 97.5 & Yes & 7 & 3.5 \\
\hline \multicolumn{3}{|l|}{ Thrombocytopaenia: } & No & 193 & 96.5 \\
\hline Yes & 3 & 1.5 & \multirow{2}{*}{\multicolumn{3}{|c|}{$\begin{array}{l}\text { Skin and subcutaneous } \\
\text { tissue disorders: } \\
\text { Alopecia: }\end{array}$}} \\
\hline No & 197 & 98.5 & & & \\
\hline \multicolumn{3}{|l|}{ Smell disorders: } & Yes & 25 & 12.5 \\
\hline \multicolumn{3}{|l|}{ Anosmia: } & No & 175 & 87.5 \\
\hline Yes & 2 & 1 & \multicolumn{3}{|l|}{ Rash acneiform: } \\
\hline No & 198 & 99 & Yes & 9 & 4.5 \\
\hline \multicolumn{3}{|l|}{ Gastrointestinal disorders: } & No & 191 & 95.5 \\
\hline Diarrhoea: & & & & & \\
\hline Yes & 32 & 16.0 & & & \\
\hline No & 168 & 84.0 & & & \\
\hline
\end{tabular}

Qualitative variables: number (percentage). Quantitative variables: Normal distribution: mean \pm standard deviation. Non-normal distribution: $P_{50}\left[P_{25}, P_{75}\right]$. 
45 years $(35,53), 161$ were female $(161 / 200 ; 80.5 \%)$, and 143 were non-smokers (143/200; 71.5\%). The median of the duration on MTX treatment was 46 months $(17,88)$. As regards the baseline RF value, it was positive for $68.3 \%(63 / 199)$ of patients, and for RA activity analysed by DAS28 value the mean obtained was $5.42 \pm 1.15$. The grade $3-$ 4 toxicity profile value was: $6.0 \%(12 / 200)$ anaemia, 7.5\% (15/200) neutropaenia, 2.5\% (5/200) macrocytosis, $1.5 \%(3 / 200)$ thrombocytopenia, $1 \%$ (2/200) anosmia, 16.0\% (32/200) diarrhoea, $23.0 \%(46 / 200)$ nausea and vomiting, $11.0 \%$ (22/200) mucositis, 46.4\% (90/200) liver failure, 9.0\% (18/194) dizziness, 10.0\% (20/200) headache, $0.5 \%(1 / 200)$ anxiety, $1.5 \%(3 / 200)$ metrorrhagia, $3.5 \%$ (7/200) pulmonary fibrosis, $12.5 \%$ (25/200) alopecia, and 4.5\% (9/200) acneiform rash (Table I).

\section{Influence of clinical-pathological characteristics on toxicity}

Nausea and vomiting showed a statistically significant association with treatment duration ( $p=0.0423$; OR $=2.13$; 95\% Cl: $1.03-4.54$ ) (Supplementary Table SI). No association was observed between the other toxicities and patient clinical-pathological characteristics (Supplementary Tables SII-SXVI).

\section{Genotyping distribution}

The distribution of all the polymorphisms studied match what is expected as per the Hardy-Weinberg equilibrium model (Supplementary Table SXVII). The linkage disequilibrium $D^{\prime}$ and $r^{2}$ values are shown in Supplementary Table SXVIII.

\section{Influence of polymorphisms on toxicity}

\section{Haematological toxicity}

Bivariate analysis showed that patients with CC genotype for ABCC2 rs4148396 polymorphism were at greater risk of developing macrocytosis ( $p=0.0022$ ) (Supplementary Table SXIX). The multivariate logistic regression model revealed the influence of this polymorphism on macrocytosis (Table II). In the bivariate analysis, MTHFR rs1801133 was associated with anaemia. In particular, patients with the TT genotype were at greater risk of anaemia ( $p=0.0328 ; \mathrm{OR}=3.70 ; 95 \% \mathrm{Cl}: 13-12.09)$ (Supplementary Table SXX). This association was also clear in the multivariate logistic regression analysis (Table II). Other haematological toxicities (neutropaenia and thrombocytopaenia) showed no significant association with the polymorphisms analysed (Supplementary Tables SXXI, SXXII).

\section{Nervous system toxicity}

Bivariate analysis showed that the MTHFR rs1801133 and $A B C C 2$ rs4148396 gene polymorphisms were associated with a higher risk of dizziness and headaches, respectively. Specifically, patients with MTHFR rs1801133-T allele were at greater risk of experiencing dizziness ( $p=0.0355$; $\mathrm{OR}=8.15 ; 95 \% \mathrm{Cl}:$ 1.06-62.75) (Supplementary Table SXXIII). Similarly, patients with $A B C C 2$ rs4148396-TT genotype were at greater risk of experiencing headaches $(p=0.0496$; OR $=2.67$; 95\%Cl: 0.01-7.01) (Supplementary Table SXXIV). Multivariate logistic regression analysis was conducted to evaluate the impact of these polymorphisms on nervous system toxicity, and both were found to be statistically significant (Table II).

\section{Other toxicity subtypes}

Bivariate analysis showed that patients with MTHFR rs1801131-C allele were at greater risk of developing mucositis and acneiform rash $(p=0.02765 ; \mathrm{OR}=3.02 ; 95 \% \mathrm{Cl}: 1.20-7.57$ and $p=0.0307 ; \mathrm{OR}=5.74 ; 95 \% \mathrm{Cl}: 1.16-28.27$, respectively) (Supplementary Tables SXXV, SXXVI). The multivariate logistic regression model showed that MTHFR rs1801131 was the only independent factor associated with developing mucositis and

Table II. The influence of gene polymorphisms on toxicity

\begin{tabular}{|c|c|c|}
\hline Parameter & OR $(95 \% \mathrm{Cl})$ & $P$-value \\
\hline \multicolumn{3}{|l|}{ Anaemia: } \\
\hline MTHFR rs1801133-TT & $3.70(1.10-12.43)$ & 0.0304 \\
\hline \multicolumn{3}{|l|}{ Anosmia: } \\
\hline MTR rs1805087-CC & 98.00 (3.16-Inf) & 0.0038 \\
\hline \multicolumn{3}{|l|}{ Alopecia: } \\
\hline MTHFD1 rs2236225-T & $4.47(1.41-20.24)$ & 0.0229 \\
\hline MTHFR rs1801131-CC & $6.20(1.84-20.53)$ & 0.0025 \\
\hline \multicolumn{3}{|l|}{ Mucositis: } \\
\hline MTHFR rs1801131-C & $3.02(1.22-7.91)$ & 0.0188 \\
\hline \multicolumn{3}{|l|}{ Liver failure: } \\
\hline MTHFD1 rs2236225-TT & $2.34(1.14-4.96)$ & 0.0229 \\
\hline \multicolumn{3}{|l|}{ Dizziness: } \\
\hline MTHFR rs1801133-C & $8.15(1.61-148.68)$ & 0.0438 \\
\hline \multicolumn{3}{|l|}{ Headache: } \\
\hline ABCC2 rs4148396-TT & $2.67(0.98-6.94)$ & 0.0466 \\
\hline \multicolumn{3}{|l|}{ Rash acneiform: } \\
\hline MTHFR rs1801131-C & $5.74(1.34-39.21)$ & 0.0322 \\
\hline
\end{tabular}


María José Zarzuelo Romero, María del Mar Maldonado Montoro, Cristina Pérez Ramírez, Noelia Márquez Pete, Almudena Sánchez Martín, Fernando Martínez Martínez, Miguel Ángel Calleja Hernández, María Carmen Ramírez Tortosa, Alberto Jiménez Morales

acneiform rash (Table II). In the bivariate analysis, patients with MTR rs1805087-CC genotype were at greater risk of developing anosmia ( $p=0.0298$; $\mathrm{RR}=98.00 ; 95 \% \mathrm{Cl}: 4.41-2180.05)$ (Supplementary Table SXXVII), which was confirmed in the multivariate analysis (Table II). In the bivariate analysis, patients with MTHFD1 rs2236225-T allele and MTHFR rs1801131-CC genotype were at greater risk of developing alopecia $(p=0.0248 ; \mathrm{OR}=3.83$; $95 \% \mathrm{Cl}: 1.10-13.30$ and $p=0.0072 ; \mathrm{OR}=5.11$; $95 \% \mathrm{Cl}: 1.37-17.70$, respectively) (Supplementary Table SXXVIII), which was statistically significant in the multivariate analysis (Table II). Liver failure was associated with MTHFD1 rs2236225 gene polymorphism. Patients with MTHFD1 rs2236225TT genotype showed higher toxicity due to liver failure ( $p=0.0332$; OR $=2.34 ; 95 \% \mathrm{Cl}: 1.12-4.86$ ) (Supplementary Table SXXIX). The multivariate logistic regression analysis showed that the MTHFD1 rs2236225 gene polymorphism was the only independent factor associated with liver failure (Table II).

For the remaining polymorphisms, no significant associations were found between the genotype and appearance of toxicity (Supplementary Tables SXXX-SXXXIV).

\section{Discussion}

Over 2 million patients experience adverse reactions to medication annually, with around 197,000 deaths as a result [46]. In the case of RA, MTX is the first-line treatment, but $30 \%$ of RA patients on MTX therapy cease treatment due to side effects such as liver failure or gastrointestinal disorders. Furthermore, there is considerable variability between patients as regards developing toxicity, which limits treatment [47-50]. Among the causes leading to this variability are polymorphisms in the genes in the MTX metabolic pathway [51-59].

This study included 200 RA patients in a single institution, who had been on MTX treatment for at least one month, with a view to investigating the influence of polymorphisms in $A B C B 1, A B C C 2$, MTHFR, MTR, MTHFD1, and TLR4 genes on the risk of developing drug-related toxicity. Among these patients, MTHFR rs1801133-C allele and TT genotype, MTHFR rs1801131-C allele and CC genotype, MTR rs1805087-CC genotype, MTHFD 1 rs2236225-TT genotype and T allele, and ABCC2 rs4148396-TT genotype are all predictors of at least one grade 3-4 adverse reaction developing (Table II).

The influence of polymorphisms in MTHFR (rs1801131 and rs1801133) on MTX toxicity has been extensively researched $[31,60,61]$. In our study, the polymorphism rs1801133 has been associated with the development of anaemia in patients with the TT genotype $(p=0.0304$ $\mathrm{OR}=3.70 ; 95 \% \mathrm{Cl}: 1.10-12.43)$ and of experiencing dizziness in patients with the $\mathrm{C}$ allele $(p=0.0438$ $\mathrm{OR}=8.15 ; 95 \% \mathrm{Cl}: 1.61-148.68)$. No previous studies have assessed the effect of this polymorphism on both toxicity subtypes in RA patients on MTX therapy. In line with our findings, a previous study in India on 236 RA patients treated with MTX found a link between the $T$ allele for MTHFR rs1801133 and the development of general toxicity $(R R=2.01$; $95 \% \mathrm{Cl}: 1.09-3.70)$, primarily with increased levels of liver enzymes $(R R=2.38 ; 95 \% \mathrm{Cl}: 1.06-5.34)$ [28]. Similarly, a study on Caucasian patients with osteosarcoma (63 patients) and acute lymphoblastic leukaemia (52 patients) on MTX therapy showed a link between the T allele and liver toxicity $(p=0.04$; $\mathrm{OR}=1.8 ; 95 \% \mathrm{Cl}: 1.0-3.2)$ [61]. In relation to MTHFR rs1801131, our study revealed a significant link between the $C$ allele and the risk of developing acneiform rash ( $p=0.0322$; OR $=5.74$; $95 \% \mathrm{Cl}: 1.34-39.21)$ and mucositis $(p=0.0188$; $\mathrm{OR}=3.02 ; 95 \% \mathrm{Cl}: 1.22-7.91)$. Patients carrying the CC genotype also showed greater risk of developing alopecia $(p=0.0072 ; \mathrm{OR}=5.11 ; 95 \% \mathrm{Cl}$ : 1.37-17.70). The link between this polymorphism and the development of dermatological toxicity has not been previously studied. However, in line with our findings, a study on 1004 Asian patients with lung cancer receiving platinum-based chemotherapy found a link between patients with the CT genotype and the development of gastrointestinal toxicity ( $p=0.004, \mathrm{OR}=0.40 ; 95 \% \mathrm{Cl}$ : 0.22-0.75) [20].

In relation to MTHFD1 rs2236225 gene polymorphism, we found an association between the MTHFD 1 rs2236225-T allele and the risk of alopecia ( $p=0.0248 ; \mathrm{OR}=3.83 ; 95 \% \mathrm{Cl}: 1.10-13.30)$ as well as between the MTHFD1 rs2236225-TT genotype and risk of liver failure $(p=0.0229$; OR = 2.34; $95 \% \mathrm{Cl}: 1.14-4.96)$. Liver failure is the most frequently occurring adverse reaction and therefore the one that causes the most concern for MTX treatment, and alopecia is another frequent side effect, but there are no previous studies that assess the effect of MTHFD1 rs2236225 polymorphism on liver toxicity or alopecia in RA patients. However, its effect in 41 patient from Slovenia with pleural mesothelioma has been assessed regarding response to pemetrexed treatment, which was found to be lower in patients with the T allele $(p=0.0005 ; \mathrm{OR}=0.12 ; 95 \% \mathrm{Cl}: 0.03-0.54)$ [62].

As regards $A B C C 2$ rs4148396 polymorphism, our study showed a link between the TT genotype and greater risk of experiencing headaches ( $p=$ 0.0466; OR = 2.67; 95\% Cl: 0.98-6.94). The effect of this polymorphism on central nervous system toxicity has not been studied previously in RA patients, although its association with toxicity has 
been evaluated in a study on 154 Caucasian patients with colorectal cancer receiving chemotherapy (5-fluorouracil/leucovorin/oxaliplatin), which revealed a correlation between the $T$ allele of $A B C C 2$ rs4148396 and neurotoxicity $(p=0.0048$; $\mathrm{OR}=4.69 ; 95 \% \mathrm{Cl}: 1.60-13.74)[63]$.

Another of the MTX metabolic pathway polymorphisms analysed is MTR rs 1805087 . We found a link between the CC genotype of this polymorphism and anosmia ( $p=0.0038$; OR = 98.00; 95\% Cl: 3.16-infinite); however, the sample size was only 2 patients. There are no previous studies that evaluate the role of this polymorphism in developing anosmia, but its role as a biomarker for gastrointestinal disorders and liver toxicity has been evaluated in 405 European patients, and although no significant differences were found in this respect, they were found in the time taken for disease to become inactive ( $p=0.042$; OR $=1.64$; 95\% Cl: 1.02-2.63) [64].

Lastly, other polymorphisms analysed for which we found no significant differences are $A B C B 1$ rs1045642 and TLR4 rs4986790. In line with our findings, various studies have assessed the role of the $A B C B 1$ rs1045642 polymorphism in patients receiving platinum-based chemotherapy. A study on 120 Caucasian patients with colorectal cancer on oxaliplatin therapy evaluated the effect of $A B C B 1$ rs1045642 gene polymorphism on neurotoxicity, finding no significant differences $(p=$ 0.951; OR =0.97; 95\% Cl: 0.39-2.41) [65]. Another study on 141 patients with non-small-cell lung cancer receiving carboplatin/cisplatin treatment studied the effect of this polymorphism on different toxicity sub-types (asthenia, gastrointestinal toxicity, liver toxicity, infection, nephrotoxicity, and neurotoxicity) and found no significant association [66]. For TLR4 rs4986790 gene polymorphism, a study on 1481 RA patients found no significant association between this polymorphism and toxicity relating to cardiovascular risk, which is in line with our findings [67].

The patients included in our study were recruited from the same hospital, which ensures sample homogeneity as regards treatment and period of administration, and toxicity data. Its main limitation relates to sample size, due to the small number of patients showing a link between some of the polymorphisms described and toxicity.

This notwithstanding, and given that there are currently no tests available for predicting MTX toxicity, it may be concluded that pharmacogenetic studies of the polymorphisms involved in MTX metabolic pathways may be clinically useful for rheumatologists as an aid for making decisions regarding therapy, such as dose adjustment or concomitant administration of folic or folinic acid, or an alternative treatment. In this way, therapeu- tic algorithms for RA that may integrate clinical, genetic, and other biomarker data are critically important to individualise and optimise therapy with antirheumatic agents. In this regard, the next crucial step is the clinical verification of these promising biomarkers using studies that assess multiple SNPS, longer-term follow-up, and larger sample sizes. Therefore, further research is needed to clarify the true role of these polymorphisms in the toxicity to MTX therapy in AR patients.

Moreover, along with the growing pharmacogenetic knowledge in rheumatology, there is increasing difficulty to explain to physicians the use, advantages, and disadvantages of pharmacogenetics and how to interpret and apply genetic test result to guide drug therapy decisions. Thus, effective health education for physicians is required for a successful choice and/or adjustment of antirheumatic agents and for an understandable information towards the patients.

In conclusion, these results suggest that RA patients treated with MTX, who have MTHFR rs1801133-TT genotype, are at higher risk of developing anaemia. Patients with MTHFR rs1801133-C allele are at greater risk of experiencing dizziness, and patients with MTHFR rs1801131-C allele or CC genotype are at greater risk of developing mucositis, acneiform rash, and alopecia. Our results also revealed that patients with MTHFD 1 rs2236225-T allele or TT genotype are at greater risk of liver failure and alopecia. Similarly, the TT genotype of ABCC2 rs4148396 gene polymorphism conferred higher risk of suffering headaches in our patients.

\section{Acknowledgments}

María del Mar Maldonado Montoro and Cristina Pérez Ramírez contributed equally to the work. Ángel Calleja Hernández, María Carmen Ramírez Tortosa and Alberto Jiménez Morales also contributed equally to the work.

\section{Conflict of interest}

The authors declare no conflict of interest.

\section{References}

1. McInnes IB, Schett G. The pathogenesis of rheumatoid arthritis. N Engl J Med 2011; 365: 2205-19.

2. Malinowski D, Paradowska-Gorycka A, Safranow K, Pawlik A. Interleukin-21 gene polymorphism rs2221903 is associated with disease activity in patients with rheumatoid arthritis. Arch Med Sci 2017; 13: 1142-7.

3. Baczyk G, Kozlowska K. The role of demographic and clinical variables in assessing the quality of life of outpatients with rheumatoid arthritis. Arch Med Sci 2018; 14: 1070-9.

4. Balbaloglu O, Ozcan SS. Is pentraxin 3 level an effective biomarker in disease activity in patients with rheumatoid arthritis? Arch Med Sci 2020; 16: 81-6. 
5. Dervisevic A, Resic H, Sokolovic S, et al. Leptin is associated with disease activity but not with anthropometric indices in rheumatoid arthritis patients. Arch Med Sci 2018; 14: 1080-6.

6. Burmester GR, Pope JE. Novel treatment strategies in rheumatoid arthritis. Lancet 2017; 389: 2338-48.

7. Batko B, Stajszczyk M, Swierkot J, et al. Prevalence and clinical characteristics of rheumatoid arthritis in Poland a nationwide study. Arch Med Sci 2019; 15: 134-40.

8. Tlustochowicz M, Sliwczynski AM, Brzozowska M, Teter Z, Marczak M. Sequentiality of treatment in the rheumatoid arthritis drug programme in the years 2009-2014. Arch Med Sci 2018; 14: 569-71.

9. Ma K, Li L, Liu C, Zhou L, Zhou X. Efficacy and safety of various anti-rheumatic treatments for patients with rheumatoid arthritis: a network meta-analysis. Arch Med Sci 2019; 15: 33-54.

10. Owen S, Lunt M, Bowes J, et al. MTHFR gene polymorphisms and outcome of methotrexate treatment in patients with rheumatoid arthritis: analysis of key polymorphisms and meta-analysis of C677T and A1298C polymorphisms. Pharmacogenomics J 2013 13: 137.

11. Felson DT, Anderson JJ, Meenan RF. The comparative efficacy and toxicity of second-line drugs in rheumatoid arthritis. Results of two metaanalyses. Arthritis Rheum 1990; 33: 1449-61.

12. Kremer JM. Toward a better understanding of methotrexate. Arthritis Rheum 2004; 50: 1370-82.

13. Aletaha D, Smolen JS. The rheumatoid arthritis patient in the clinic: comparing more than 1,300 consecutive DMARD courses. Rheumatology 2002; 41: 1367-74.

14. Salliot C, van der Heijde D. Long-term safety of methotrexate monotherapy in patients with rheumatoid arthritis: a systematic literature research. Ann Rheum Dis 2009; 68: 1100-4

15. Tian $\mathrm{H}$, Cronstein BN. Understanding the mechanisms of action of methotrexate: implications for the treatment of rheumatoid arthritis. Bull NYU Hosp Jt Dis 2007; 65: 168-73.

16. Wang W, Zhou H, Liu L. Side effects of methotrexate therapy for rheumatoid arthritis: a systematic review. Eur J Med Chem 2018; 158: 502-16.

17. Labadie JG, Hashim R, Raheel S, Awad L, Jain M. A 2018 approach to combating methotrexate toxicity folic acid and beyond. Bull Hosp Jt Dis 2018; 76: 151-5.

18. Weinblatt ME, Kaplan H, Germain BF, et al. Methotrexate in rheumatoid arthritis. A five-year prospective multicenter study. Arthritis Rheum 1994; 37: 1492-8.

19. Walker AM, Funch D, Dreyer NA, et al. Determinants of serious liver disease among patients receiving low-dose methotrexate for rheumatoid arthritis. Arthritis Rheum 1993; 36: 329-35.

20. Li X, Shao M, Wang S, et al. Heterozygote advantage of methylenetetrahydrofolate reductase polymorphisms on clinical outcomes in advanced non-small cell lung cancer (NSCLC) patients treated with platinum-based chemotherapy. Tumour Biol 2014; 35: 11159-70.

21. Shao W, Yuan Y, Li Y. Association between MTHFR C677T polymorphism and methotrexate treatment outcome in rheumatoid arthritis patients: a systematic review and meta-analysis. Genetic Testing Mol Biomarkers 2017; 21: 275-85.

22. Lee Y, Bae SC, Song G. Association of the ABCB1 C3435T polymorphism with responsiveness to and toxicity of DMARDs in rheumatoid arthritis. Zeitschrift fur Rheumatologie 2016; 75: 707-15.
23. Bae SC, Lee YH. TYMS polymorphisms and responsiveness to or toxicity of methotrexate in rheumatoid arthritis. Zeitschrift fur Rheumatologie 2018; 77: 824-32.

24. Bohanec Grabar P, Logar D, Lestan B, Dolzan V. Genetic determinants of methotrexate toxicity in rheumatoid arthritis patients: a study of polymorphisms affecting methotrexate transport and folate metabolism. Eur J Clin Pharmacol 2008; 64: 1057-68.

25. Inoue K, Yuasa H. Molecular basis for pharmacokinetics and pharmacodynamics of methotrexate in rheumatoid arthritis therapy. Drug Metabol Pharmacokinet 2014; 29: 12-9.

26. Dogru A, Naziroglu M, Cig B. Modulator role of infliximab and methotrexate through the transient receptor potential melastatin 2 (TRPM2) channel in neutrophils of patients with rheumatoid arthritis: a pilot study. Arch Med Sci 2019; 15: 1415-24.

27. Brinker RR, Ranganathan P. Methotrexate pharmacogenetics in rheumatoid arthritis. Clin Exp Rheumatol 2010; 28 (5 Suppl 61): S33-9.

28. Chaabane S, Messedi M, Akrout R, et al. Association of hyperhomocysteinemia with genetic variants in key enzymes of homocysteine metabolism and methotrexate toxicity in rheumatoid arthritis patients. Inflammation Res 2018; 67: 703-10.

29. van Ede AE, Laan RF, Blom HJ, et al. The C677T mutation in the methylenetetrahydrofolate reductase gene: a genetic risk factor for methotrexate-related elevation of liver enzymes in rheumatoid arthritis patients. Arthritis Rheum 2001; 44: 2525-30.

30. Dervieux T, Wessels JA, van der Straaten T, et al. Genegene interactions in folate and adenosine biosynthesis pathways affect methotrexate efficacy and tolerability in rheumatoid arthritis. Pharmacogenet Genom 2009; 19: 935-44.

31. Mena JP, Salazar-Paramo M, Gonzalez-Lopez L, et al. Polymorphisms C677T and A1298C in the MTHFR gene in Mexican patients with rheumatoid arthritis treated with methotrexate: implication with elevation of transaminases. Pharmacogenomics J 2011; 11: 287-91.

32. Krajinovic M. MTHFD1 gene: role in disease susceptibility and pharmacogenetics. Pharmacogenomics 2008; 9: 829-32.

33. Leclerc D, Campeau E, Goyette P, et al. Human methionine synthase: cDNA cloning and identification of mutations in patients of the cblG complementation group of folate/cobalamin disorders. Human Mol Genet 1996; 5: 1867-74.

34. Zara-Lopes T, Galbiatti-Dias ALS, Castanhole-Nunes MMU, et al. Polymorphisms in MTHFR, MTR, RFC1 and CssS genes involved in folate metabolism and thyroid cancer: a case-control study. Arch Med Sci 2019; 15: 522-30.

35. Pawlik A, Wrzesniewska J, Fiedorowicz-Fabrycy I, Gawronska-Szklarz B. The MDR1 3435 polymorphism in patients with rheumatoid arthritis. Int J Clin Pharmacol Ther 2004; 42: 496-503.

36. Chen Y, Zou K, Sun J, Yang Y, Liu G. Are gene polymorphisms related to treatment outcomes of methotrexate in patients with rheumatoid arthritis? A systematic review and meta-analysis. Pharmacogenomics 2017; 18: 175-95.

37. Muralidharan N, Antony PT, Jain VK, Mariaselvam CM, Negi VS. Multidrug resistance 1 (MDR1) 3435C> T gene polymorphism influences the clinical phenotype and methotrexate-induced adverse events in South Indian Tamil rheumatoid arthritis. Eur J Clinl Pharmacol 2015; 71: 959-65. 
38. Rau T, Erney B, Göres R, Eschenhagen T, Beck J, Langer T. High-dose methotrexate in pediatric acute lymphoblastic leukemia: impact of $\mathrm{ABCC} 2$ polymorphisms on plasma concentrations. Clin Pharmacol Ther 2006; 80: 468-76.

39. Ranganathan P, Culverhouse R, Marsh S, et al. Methotrexate (MTX) pathway gene polymorphisms and their effects on MTX toxicity in Caucasian and African American patients with rheumatoid arthritis. J Rheumatol 2008; 35: 572-9.

40. Kooloos WM, Wessels JA, van der Straaten T, Allaart CF, Huizinga TW, Guchelaar HJ. Functional polymorphisms and methotrexate treatment outcome in recent-onset rheumatoid arthritis. Pharmacogenomics 2010; 11: 163-75.

41. Walker UA, Jaeger VK, Chatzidionysiou K, et al. Rituximab done: what's next in rheumatoid arthritis? A European observational longitudinal study assessing the effectiveness of biologics after rituximab treatment in rheumatoid arthritis. Rheumatology 2016; 55: 230-6.

42. Smolen JS, Landewe R, Bijlsma J, et al. EULAR recommendations for the management of rheumatoid arthritis with synthetic and biological disease-modifying antirheumatic drugs: 2016 update. Ann Rheum Dis 2017; 76: 960-77.

43. Prevoo ML, van't Hof MA, Kuper HH, van Leeuwen MA, van de Putte LB, van Riel PL. Modified disease activity scores that include twenty-eight-joint counts. Development and validation in a prospective longitudinal study of patients with rheumatoid arthritis. Arthritis Rheum 1995; 38: 44-8.

44. Jana M, Pahan K. IL-12 p40 homodimer, but not IL-12 p70, induces the expression of IL-16 in microglia and macrophages. Mol Immunol 2009; 46: 773-83.

45. Purcell S, Neale B, Todd-Brown K, et al. PLINK: a toolset for whole-genome association and population-based linkage analysis. Am J Human Genet 2007; 81: 559-75.

46. Lazarou J, Pomeranz BH, Corey PN. Incidence of adverse drug reactions in hospitalized patients: a meta-analysis of prospective studies. JAMA 1998; 279: 1200-5.

47. Kerstens PJ, Boerbooms AM, Jeurissen ME, Fast JH, Assmann KJ, van de Putte LB. Accelerated nodulosis during low dose methotrexate therapy for rheumatoid arthritis. An analysis of ten cases. J Rheumatol 1992; 19: 867-71.

48. McKendry RJ, Dale P. Adverse effects of low dose methotrexate therapy in rheumatoid arthritis. J Rheumatol 1993; 20: 1850-6.

49. Lucas CJ, Dimmitt SB, Martin JH. Optimising low-dose methotrexate for rheumatoid arthritis - a review. $\mathrm{Br}$ J Clin Pharmacol 2019; 85: 2228-34.

50. Friedman B, Cronstein B. Methotrexate mechanism in treatment of rheumatoid arthritis. Joint Bone Spine 2019; 86: 301-7.

51. Aggarwal P, Naik S, Mishra KP, Aggarwal A, Misra R. Correlation between methotrexate efficacy \& toxicity with C677T polymorphism of the methylenetetrahydrofolate gene in rheumatoid arthritis patients on folate supplementation. Indian J Med Res 2006; 124: 521-6.

52. Haagsma CJ, Blom HJ, van Riel PL, et al. Influence of sulphasalazine, methotrexate, and the combination of both on plasma homocysteine concentrations in patients with rheumatoid arthritis. Ann Rheum Dis 1999; 58: 79-84.

53. Kim SK, Jun JB, El-Sohemy A, Bae SC. Cost-effectiveness analysis of MTHFR polymorphism screening by polymerase chain reaction in Korean patients with rheumatoid arthritis receiving methotrexate. J Rheumatol 2006; 33: 1266-74.
54. Kumagai K, Hiyama K, Oyama T, Maeda H, Kohno N. Polymorphisms in the thymidylate synthase and methylenetetrahydrofolate reductase genes and sensitivity to the low-dose methotrexate therapy in patients with rheumatoid arthritis. Int J Mol Med 2003; 11: 593-600.

55. Kurzawski M, Pawlik A, Safranow K, Herczynska M, Drozdzik M. 677C $>$ T and 1298A $>C$ MTHFR polymorphisms affect methotrexate treatment outcome in rheumatoid arthritis. Pharmacogenomics 2007; 8: 1551-9.

56. Taniguchi A, Urano W, Tanaka E, et al. Validation of the associations between single nucleotide polymorphisms or haplotypes and responses to disease-modifying antirheumatic drugs in patients with rheumatoid arthritis: a proposal for prospective pharmacogenomic study in clinical practice. Pharmacogenet Genomics 2007; 17: 383-90.

57. Urano W, Taniguchi A, Yamanaka H, et al. Polymorphisms in the methylenetetrahydrofolate reductase gene were associated with both the efficacy and the toxicity of methotrexate used for the treatment of rheumatoid arthritis, as evidenced by single locus and haplotype analyses. Pharmacogenetics 2002; 12: 183-90.

58. Wessels JA, de Vries-Bouwstra JK, Heijmans BT, et al. Efficacy and toxicity of methotrexate in early rheumatoid arthritis are associated with single-nucleotide polymorphisms in genes coding for folate pathway enzymes. Arthritis Rheum 2006; 54: 1087-95.

59. Berkun Y, Levartovsky D, Rubinow A, et al. Methotrexate related adverse effects in patients with rheumatoid arthritis are associated with the A1298C polymorphism of the MTHFR gene. Ann Rheum Dis 2004; 63: 1227-31.

60. Dervieux T, Wessels JA, van der Straaten T, et al. Genegene interactions in folate and adenosine biosynthesis pathways affect methotrexate efficacy and tolerability in rheumatoid arthritis. Pharmacogenet Genomics 2009; 19: 935-44.

61. Hagleitner MM, Coenen MJ, Aplenc R, et al. The role of the MTHFR $677 C>T$ polymorphism in methotrexate-induced liver toxicity: a meta-analysis in patients with cancer. Pharmacogenomics J 2014; 14: 115-9.

62. Goricar K, Kovac V, Dolzan V. Polymorphisms in folate pathway and pemetrexed treatment outcome in patients with malignant pleural mesothelioma. Radiol Oncol 2014; 48: 163-72.

63. Cecchin E, D'Andrea M, Lonardi S, et al. A prospective validation pharmacogenomic study in the adjuvant setting of colorectal cancer patients treated with the 5-fluorouracil/leucovorin/oxaliplatin (FOLFOX4) regimen. Pharmacogenomics J 2013; 13: 403-9.

64. Zajc Avramovic M, Dolzan V, Toplak N, Accetto M, Lusa L, Avcin T. Relationship between polymorphisms in methotrexate pathway genes and outcome of methotrexate treatment in a cohort of 119 patients with juvenile idiopathic arthritis. J Rheumatol 2017; 44: 1216-23.

65. Nichetti F, Falvella FS, Miceli R, et al. Is a pharmacogenomic panel useful to estimate the risk of oxaliplatin-related neurotoxicity in colorectal cancer patients? Pharmacogenomics J 2019; 19: 465-72.

66. Perez-Ramirez C, Canadas-Garre M, Alnatsha A, et al. Pharmacogenetics of platinum-based chemotherapy: impact of DNA repair and folate metabolism gene polymorphisms on prognosis of non-small cell lung cancer patients. Pharmacogenomics J 2019; 19: 164-77.

67. Garcia-Bermudez M, Lopez-Mejias R, Gonzalez-Juanatey C, et al. Lack of association between TLR4 rs4986790 polymorphism and risk of cardiovascular disease in patients with rheumatoid arthritis. DNA Cell Biol 2012; 31 : 1214-20. 